\title{
THE DEPENDENCE OF SOME STRAINS OF MYCOBACTERIUM AVIUM ON MYCOBACTIN FOR INITIAL AND SUBSEQUENT GROWTH
}

\author{
P. R. J. Matthews, A. McDiarmid, P. Collins and Anne Brown \\ Institute for Research on Animal Diseases, Compton, near Newbury, Berkshire RG16 ONN
}

THE addition of mycobactin as a growth factor to various media has long been practised for the primary isolation of Mycobacterium paratuberculosis. Numerous strains of other mycobacteria that on primary culture grew only in the presence of mycobactin have been isolated in this laboratory from a wide range of farm animals and wildlife. These strains, irrespective of their origin, have taken from 1 to 6 months to grow. McDiarmid (1962) described the isolation of such strains from the wood pigeon (Columba palumbus L.) and Rankin and McDiarmid (1969) referred to similar strains from various species of free-living British deer. Subsequently, Matthews (1969) showed that, by means of a medium containing mycobactin, the number of isolates of mycobacteria from the lymph nodes of the heads of pigs could be increased by $14.5 \%$; the growth properties of some slow-growing mycobactindependent strains in many ways resembled those of $M$. paratuberculosis.

This paper reports further observations on the mycobactin requirements of certain Mycobacterium avium strains $(a)$ at primary isolation, $(b)$ in experiments in which small inocula were employed, and $(c)$ at re-isolation from chickens several weeks after experimental infection.

\section{MATERIALS AND METHODS}

Medium. The medium was similar to that described by Stuart (1965). To $96.0 \mathrm{ml}$ of Stuart's basal medium were added $4.0 \mathrm{ml}$ of $9.0 \%(\mathrm{w} / \mathrm{v})$ bovine albumin (Armour Laboratories) and crude mycobactin prepared from Mycobacterium phlei to give a final concentration of $3.0 \mu \mathrm{g}$ per ml.

Bacterial strains. The origin of the 10 strains of mycobacteria employed is shown in table I. The cultures were originally isolated from lymph-nodes and other tissues after treatment with $5.0 \%(\mathrm{w} / \mathrm{v})$ oxalic acid. The strains were identified by the agglutination method (Schaefer, 1965). Each had undergone numerous subcultures.

Comparison of growth and viable counts. Ten-fold dilutions were prepared from suspensions $(10 \mathrm{mg}$ per $\mathrm{ml})$ of the bacteria previously stored at $-70^{\circ} \mathrm{C}$. A standard drop $(0.02 \mathrm{ml})$ was inoculated from each dilution on each of two plates of medium containing mycobactin and on two plates without mycobactin. Viable counts were then calculated from suitable dilutions after incubation at $37^{\circ} \mathrm{C}$. The methods for preparing the suspensions of mycobateria $(10 \mathrm{mg}$ per $\mathrm{ml})$ containing known numbers of viable units have been described by Matthews and Collins (1978). Chickens were inoculated intravenously with known numbers of viable units as shown in table II.

\section{RESULTS}

The mycobactin requirements of 10 strains of $M$. avium from various sources on primary isolation and in ten-fold dilutions of subcultures are shown in table I. Four strains gave similar results on media with and without mycobactin.

The six other strains produced a fine confluent growth at the $10^{1}$ or $10^{2}$ dilutions on the medium without mycobactin, but no evidence of growth was seen from the higher dilutions. However, when the same six strains were plated out on medium containing mycobactin, growth was greatly improved and viable counts could be calculated from the numbers of colonies that grew from dilutions of $10^{5}$ or $10^{6}$.

Received 18 June 1976; accepted 27 Sept. 1976.

J. MED. MICROBIOL.—VOL. 11 (1977) 


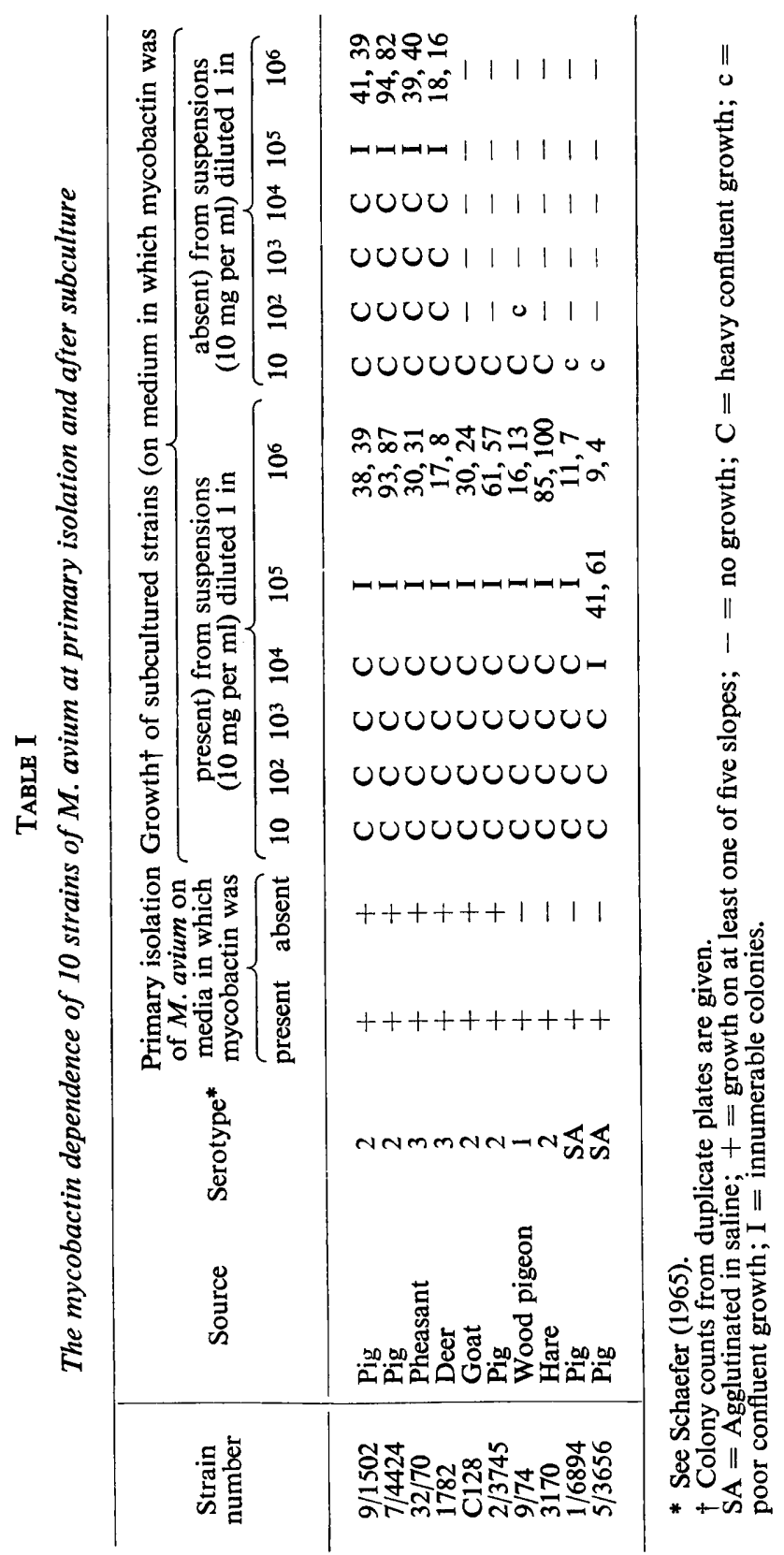




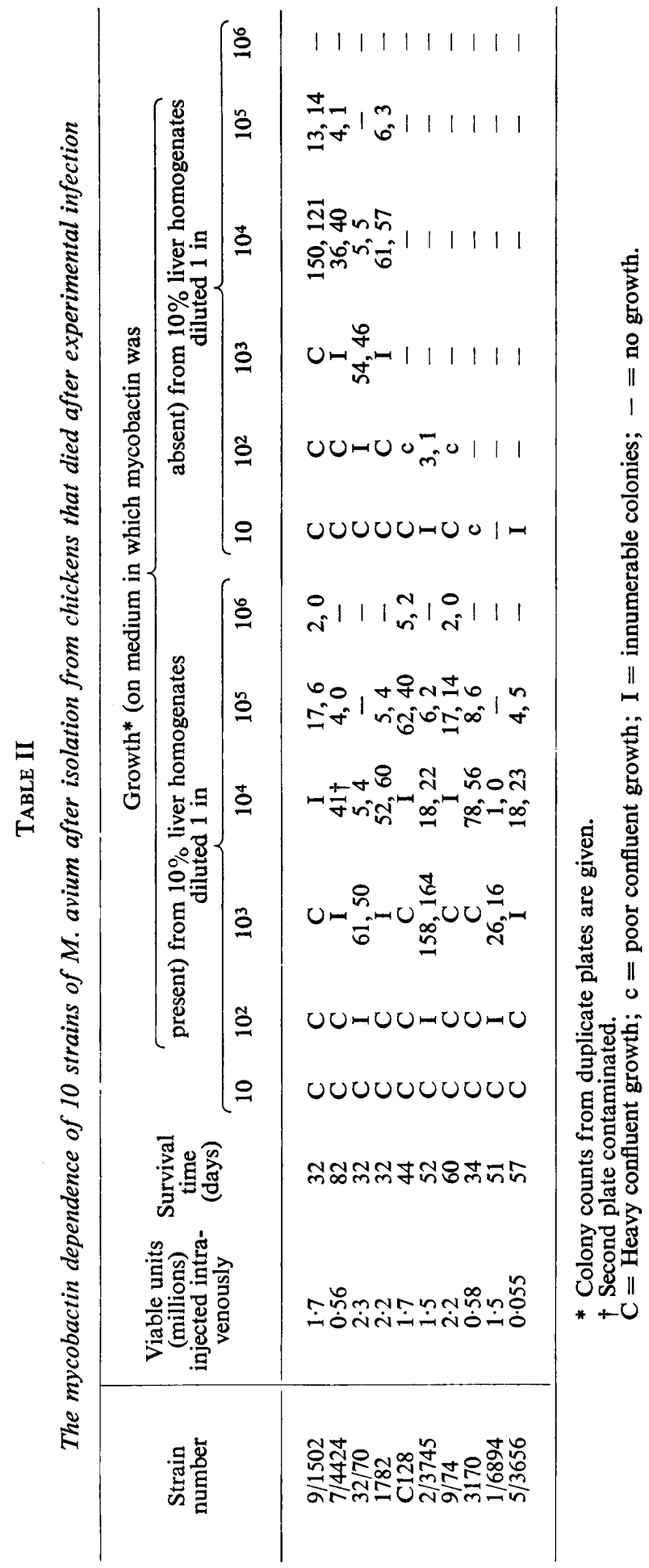


Table II gives the results of culturing, on medium with and without mycobactin, decimal dilutions of $10 \%(\mathrm{w} / \mathrm{v})$ liver homogenates from 10 chickens that died after experimental infection with pure cultures of the 10 strains of $M$. avium. All the birds died within the 8-12week period usually associated with virulent $M$. avium strains. As in the experiment recorded in table I, the viable counts of four strains (nos. 9/1502, 7/4424, 32/70 and 1782) were unaffected by the presence of mycobactin in the medium. However, the results obtained with the other six strains clearly illustrate that media containing mycobactin are needed to avoid the risk of false negative results when only small numbers of bacteria are present in the tissues.

\section{Discussion}

The strains studied were originally isolated on Stuart's medium containing mycobactin $3 \mu \mathrm{g}$ per ml, derived from $M$. phlei. Numerous subcultures were made before storage at $-70^{\circ} \mathrm{C}$, but it is not thought that this led to mycobactin dependence; such dependence has been detected in fresh isolates of $M$. avium from the ileo-caecal lymph nodes of deer.

The present study shows that mycobacterial strains requiring mycobactin for growth in primary culture may either be truly dependent on mycobactin or require it only when small numbers of viable units are cultured. The term "mycobactin-dependent" as applied to many strains of mycobacteria isolated in this laboratory in the past now requires qualification. $M$. avium strains capable of being isolated in primary culture on media with or without mycobactin have been considered typical of $M$. avium, whereas those isolated only on media containing mycobactin have been referred to as "atypical".

The present observations explain the increase in the proportion of mycobacterial strains isolated from the lymph-nodes of the heads of pigs by Matthews (1969). The number of viable units in the nodes probably varied considerably and as a result the culture inocula may sometimes have contained fewer organisms than the number capable of growing without mycobactin. In the instance of pig no. 2/3745 (table I) it would seem that the number of viable units in the tissues was sufficient to enable a primary isolation to be made without the use of mycobactin, but when small inocula were used the organism was clearly mycobactindependent.

Similar observations were also made by Doble et al. (1975) to whom we supplied strain $\mathrm{C} 128$ as a typical strain of $M$. avium. Their failure to obtain viable counts on a medium without mycobactin led us to undertake the present investigation.

From our personal observations over several years we estimate that a high proportion of virulent $M$. avium strains show the characteristic of mycobactin dependence when media are inoculated with small numbers of viable units. Large inocula presumably contain sufficient mycobactin associated with the organisms to enable growth to occur.

Our observations have shown that mycobactin dependence is not confined to $M$. paratuberculosis; we now know that it occurs within the $M$. avium serotypes 1,2 and 3 of Wolinsky and Schaefer (1973) and also in a number of strains that cannot be classified within the Avium-Intracellulare serotypes 1-20. The virulence of the latter strains for chickens is inconclusive. We refer, in particular, to one such strain, H2309, isolated from a brown hare (Lepus europaeus), and similar in many ways to $M$. paratuberculosis, but incapable of producing Johne's disease experimentally in calves (Matthews and Sargent, 1977).

In the light of present knowledge we would recommend the use of media containing mycobactin in a concentration of at least $3.0 \mu \mathrm{g}$ per $\mathrm{ml}$ for the primary isolation of $M$. avium. Whether other mycobacterial species have a similar requirement is a matter for conjecture, but it is possible that further studies may reveal that greater use of mycobactin should be made in medical diagnostic laboratories, especially for the isolation of mycobacteria from patients who have undergone treatment and may harbour very few organisms.

\section{SUMMARY}

This paper demonstrates that various degrees of mycobactin dependence exist within the $M$. avium group of mycobacteria and that this characteristic is not confined to $M$. para- 
tuberculosis. The strains employed came from a wide range of animal species and all were virulent for chickens. Mycobactin dependence was observed in the $M$. avium serotypes 1, 2 and 3.

The importance of employing a medium containing mycobactin for primary isolations from tissue containing only small numbers of viable units of $M$. avium is emphasised. This observation may be of interest in relation to the primary isolation of other species of mycobacteria.

We are grateful to Mr J. Fogerty for the preparation of the media.

\section{REFERENCES}

Doble, A., Fox, A., GlynN, L. E. AND Kingston, D. 1975. The non-passage of mycobacteria from Freund's complete adjuvant granuloma depots to arthritic joints. $B r$. J. exp. Path., 56, 537.

MCDiarmid, A. 1962. Diseases of freeliving wild animals. F.A.O. Agriculture Studies, No. 57, Rome, p. 10.

Matthews, P. R. J. 1969. The use of culture medium containing mycobactin for the isolation of acid-fast organisms from pig head lymph nodes. Res. vet. Sci., 10, 104.

Matthews, P. R. J. AND Collins P. 1978. Standardisation of inocula for assessing the virulence of strains of Avium-Intracellulare mycobacteria in chickens. $J$. med. Microbiol., 11, 47.

Matthews, P. R. J. AND SARGENT, A. 1977. The isolation of mycobacteria from the Brown Hare (Lepus europaeus). Brit. vet. J., 133, 399.

RANKIN, J. D. AND MCDIARMID, A. 1969. Mycobacterial infections in freeliving wild animals Symp. Zool. Soc. Lond., No. 24, p. 119.

SCHAEFER, W. B. 1965. Serologic identification and classification of the atypical mycobacteria by their agglutination. Am. Rev. resp. Dis., 92, Suppl., 85.

StuART, P. 1965. Vaccination against Johne's disease in cattle exposed to experimental infection. Br. vet. J. 121, 289.

Wolinskey, E. AND Schaefer, W. B. 1973. Proposed numbering scheme for mycobacterial serotypes by agglutination. Int. J. syst. Bact., 23, 182. 